DOI: https://doi.org/10.24867/12FA19Damnjanovic

\title{
SPOLJNO UREĐENJE UNUTARBLOKOVSKIH PROSTORA U OKVIRU DVA BLOKA OPŠTINE VRAČAR
}

\section{EXTERIOR - LANDSCAPE ARRANGEMENT OF INTER-BLOCK SPACES WITHIN THE TWO BLOCKS OF THE MUNICIPALITY OF VRAČAR}

\author{
Višnja Damnjanović, Fakultet tehničkih nauka, Novi Sad
}

\begin{abstract}
Oblast - ARHITEKTURA I URBANIZAM
Kratak sadržaj - Konstantna urbanizacija dovela je do sve većeg nedostatka zelenila u gradovima $i$ pogoršanja ekoloških problema. Stvaranje prirodnog okruženja u gusto izgrađenim gradskim sredinama postalo je potreba. Ovaj rad se bavi analizom problema nastalih usled nedostatka pejzažno uređenih urbanih prostora, kao i prednostima istih. Komparativnom metodom su analizirani primeri dobre prakse širom sveta, a mogućnost primene pejzažnih rešenja u već izgrađenim gradskim strukturama prikazana je u dva gradska bloka opštine Vračar.
\end{abstract}

Ključne reči: održivost, ekološka svest, zeleni gradovi, unutarblokovski prostori.

Abstract - Continuous urbanization has led to a growing shortage of greenery in cities and worsening environmental problems. Creating natural environment spaces in densely built-up urban areas has become a necessity. This paper analyzes problems resulting from the lack of landscape structures in densly populated city cores. The advantages and benefits of creating these structures are discussed as well. Solutions and the good practice examples from around the world are analysed using a comparative method. Possibility of applying these structures to an already built urban ambient, two city blocks of the municipality Vračar in Belgrade, is presented.

Keywords: sustainability, ecological sense, green cities, inter-block spaces.

\section{UVOD}

Samo $13 \%$ svetskog stanovništvo je 1900 . godine živelo u gradovima, 1950 . već $29 \%$, dok je do 2008. godine taj broj porastao na $50 \%$. Proces migracija iz sela u gradove u Srbiji počinje između dva svetska rata, kada se u novoformiranoj zajednici pokreće privredni i kulturni preporod.

Migracija dostiže vrhunac nakon Drugog svetskog rata, kada gradovi preuzimaju ulogu ekonomskog, privrednog, kulturnog i obrazovnog centra.

Tako nagla urbanizacija, potpomognuta nekada nepoštovanjem osnovnih pravila planiranja i u poslednjim decenijama divljom gradnjom, dovela je do toga da je narušena ravnoteža prirodnih elemenata $u$ gradskoj sredini.

\section{NAPOMENA:}

Ovaj rad proistekao je iz master rada čiji mentor je bila dr Mirjana Sekulić, vanr.prof.
Zauzetost parcela veoma je visoka, gustina izgrađenosti u centralnim gradskim opštinama je velika, a izgrađene parkovske površine i drvoredi duž pojedinih ulica su jedini izvor zelenila.

Kao posledica svega prethodno navedenog, pejzažno urbane strukture su svedene na minimum, pogotovo $\mathrm{u}$ užim gradskim jezgrima, o njima niko ne brine, postaju deponije za odlaganje kabastog otpada ili asfaltirani parking prostori.

Pejzažne strukture u urbanim prostorima jesu i treba da predstavljaju važan segment grada, posebno ako uzmemo $\mathrm{u}$ obzir da gradovi doprinose klimatskim promenama $\mathrm{u}$ svetu, ali su i najpodložniji njihovim negativnim uticajima. Odgovornim pristupom problemu, dugoročnim planiranjem i pametnom gradnjom možemo se potruditi da maksimalno umanjimo te uticaje i očuvamo životnu sredinu [1].

Urbane zelene površine poboljšavaju kvalitet života korisnika, vizuelni karakter samih gradova i daju vrednost ambijentalnoj celini koju formiraju sa drugim činiocima urbanog okruženja. Predstavljaju prostor za rekreaciju, relaksaciju i štite od negativnih uticaja života u gradu. Pored toga što utiču na regulaciju temperature vazduha, pritisak i vazdušna strujanja, povećavaju vlažnost vazduha i štite od prekomernog osunčavanja. Značajno doprinose i smanjenju nivoa komunalne buke, sprečavaju eroziju zemljišta i generalno poboljšavaju klimatske uslove u urbanoj sredini.

Usklađivanje zakona sa tekućim klimatskim promenama i tendencijama u arhitekturi i urbanizmu dodatno bi osigurali da gradovi, zajedno sa svojim stanovnicima, ne postanu žrtve nekontrolisane i nepromišljene izgradnje. Odnos prema okruženju i ekološka svest građana su tačke na kojima bi se mogla uspostaviti buduća platforma o očuvanju i unapređenju javnih zelenih prostora u urbanim gradskim sredinama.

\section{UNUTARBLOKOVSKO ZELENILO}

Stambeni blok je definisan kao jedinstvena celina izgrađenog i otvorenog prostora [2]. Predstavlja osnovni element formiranja gradskog tkiva i urbanog razvoja grada. On je posrednik između stana i grada, privatnog $\mathrm{i}$ javnog.

Jasno ograđen stambenim jedinicama duž svog obima podseća na ostrvo odvojeno od ostatka javnog prostora. Njagova neizgrađena unutrašnjost, zbog odlika zajedničkog polujavnog prostora, može poslužiti kao 
idealno okruženje za pospešivanje socijalne interakcije. Ovakva, donekle izolovana, unutrašnja dvorišta pružaju korisnicima osećaj zajedništva i sigurnosti, dok različiti stepeni otvorenosti i propusnosti bloka doprinose njegovom javnom karakteru.

\subsection{Zatvoreni tip bloka}

Ovakvi tipovi bloka zahtevaju poseban tretman usled otežanih uslova sredine, kao što su slaba provetrenost, osunčanost i dostupnost. Dvorišne parcele omeđene visokim stambenim zgradama su često odvojene ogradama ili zauzete bespravno izgrađenim objektima malih gabarita. Rekonstrukcija unutarblokovskih prostora treba da bude usmerena ka objedinjavanju tih površina.

Tokom planiranja rešenja treba da budu zastupljene sve kategorije vegetacije - cveće, lišćari, četinari i šiblje, kao i vertikalno zelenilo. Drvenaste puzavice mogu znatno povećati estetski kvalitet fasada i ukupnu količinu zelenila, uz cveće na balkonima i terasama. Sadnja cvetnog šiblja je posebno pogodna jer doprinosi komforu čitavog prostora razbijajući sivilo urbanog gradskog jezgra. Travnate površine u ovakvim zatvorenim i osenčenim međublokovskim prostorima treba da imaju visok stepen učešća.

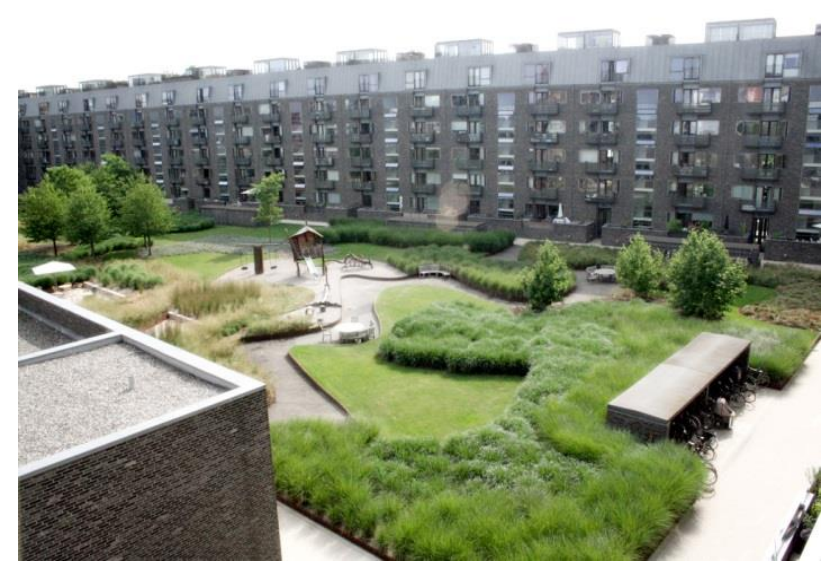

Slika 1. Primer uređenog unutarblokovskog prostora

Uklanjanjem ograda i udžerica stvaraju se mogućnosti za povećanje kvaliteta i veličine zelenih površina, koje se vegetacijom mogu izdiferencirati na prostore različite namene (odmor odraslih, igra dece...).

Organizacija zelenila treba da služi ukupnom prostornom rešenju, ali i funkcionalnoj nameni - zasenčenje, odvajanje prostora za igru dece od prostora za odmor, vizuelno naglašavanje pravaca kretanja i odvajanje nepoželjnih ekonomskih objekata.

Pored pejzažnog uređenja unutrašnjosti blokova, ovi prostori mogu biti povezani sa glavnim pešačkim pravcima van bloka kroz prizemne otvore na zgradama, uz pomoć kompozicionih i vizuelnih veza. Pešačke staze i aleje se formiraju da obezbeđuju što kraći i jednostavniji prolazak i da na optimalan način povezuju unutrašnjost bloka sa stanicama javnog gradskog prevoza, prodavnicama, školama i drugim zelenim prostorima. Primenjeni materijali za popločanje treba da se lako održavaju i da budu otporni, naročito u zonama dužeg zadržavanja i igre [3].

\subsection{Ekološki aspekt dvorišta}

Ekološki uslovi najviše zavise od visine objekata, gustine izgrađenosti, prostorne organizacije bloka i prisustva zelenila. Prirodni uslovi izuzetno doprinose socijalizaciji stanovnika. Blok je jedini strukturni element naselja koji može da obezbedi potpunu privatnost korisnika. Zato je veoma važno sačuvati privatni karakter bloka, naročito zbog sve izraženijih težnji da se poveća njegov javni karakter [4].

\section{ANALIZA RADA}

Zbog velike gustine naseljenosti i koeficijenta izgrađenosti u centralnim gradskim jezgrima javlja se nedostatak zelenila koje bi tako suvoparan prostor oplemenilo. Gradski parkovi su odavno prestali da budu dovoljni za višestruko uvećanu gustinu gradske populacije usled intenzivne izgradnje višespratnih zgrada u periodu posle Drugog svetskog rata. Drvoredi duž bulevara smanjuju se velikom brzinom zbog izgradnje parking mesta ili bašta kafića. U nedostatku drugih pejzažno urbanih struktura moramo se posvetiti kreiranju novih, manjih ali podjednako efikasnih prostora koje neće biti moguće prenameniti u budućnosti.

Vračar je jedna od 17 gradskih opština grada Beograda. U celini je izgrađena i nema prigradsko rubno zaleđe. Zauzima površinu od 292 ha, na kojoj prema popisu iz 2011. živi 56.333 stanovnika, što je 4,8\% ukupnog stanovništva glavnog grada. To je čini površinski najmanjom i najgušće naseljenom opštinom u Beogradu i Srbiji. Centralni gradski položaj upućuje i na njene osnovne funkcije - stanovanje i poslovanje.

Vračar ima svoje prednosti i mane kada su u pitanju vrednosti činilaca životne sredine. Kao sastavni deo užeg gradskog jezgra pošteđen je teških industrijskih zagađenja, velikih komunalnih čvorova i magistralnih saobraćajnica i ne nalazi se na putanji stalnih preleta aviona. Sa druge strane, mikroklima prostora je ugrožena smanjenom insolacijom i provetrenošću, velikom zauzetošću tla, nedostatkom vodenih i zelenih površina i gustim saobraćajem. Razvijanje mreže zelenila pomoglo bi u otklanjanju ili poboljšavanju ovih činilaca.

Zbog velikog indeksa izgrađenosti i broja stanovnika na tako maloj površini javljaju se brojne nepovoljnosti. Stanje životne sredine opada iz godine u godinu zbog povećane zagađenosti vazduha, nedostatka insolacije, visoke frekvencije komunalne buke, neprovetrenosti i nedostatka infrastrukture. Veliku ulogu igra i preopterećenost motornim i pešačkim saobraćajem, kao i nedostatak uređenih parkig mesta. Zbog svih ovih činilaca blokovi, a posebno oni zatvorenog tipa, su na niskom nivou uređenosti i opšte komunalne higijene. Aerozagađenje je zbog manje provetrenosti veće, posebno ako u zatvorenim blokovima dominiraju veštački materijali.

U velikom broju slučajeva unutarblokovski prostori su okupirani nelegalno izgrađenim objektima lošeg boniteta, pomoćnim objektima ili improvizovanim garažama i parking mestima. Sve to zajedno otežava i u nekim slučajevima potpuno onemogućava rekonstrukciju i reorganizaciju rekreativnih $i$ zelenih površina, a mikroekološke uslove čini daleko nepovoljnijim. 
Raščišćavanje niske i nekvalitetne izgradnje u unutrašnjosti blokova može omogućiti njihovo bolje korišćenje i bogatiju ozelenjenost.

\subsection{Postojeće stanje odabrane lokacije}

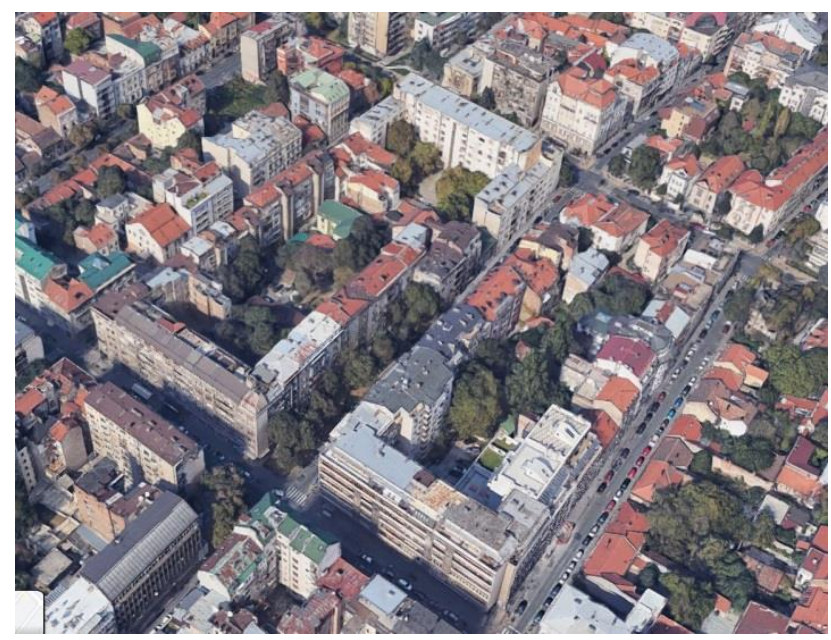

Slika 2. Pogled na odabrane blokove

Odabrani blokovi nalaze se u severozapadnom delu opštine Vračar, između Krunske, Smiljanićeve, Njegoševe i ulice Prote Mateje, a deli ih ulica Alekse Nenadovića. One povezuju blokove sa obližnjom Beogradskom ulicom koja je direktna veza sa važnim saobraćajnim čvorištima, Slavijom i Bulevarom kralja Aleksandra.

Objekti spratnosti manje od $\mathrm{P}+3$ su građeni u periodu između dva svetska rata. Više građevine su većinom iz perioda socijalizma, sa izuzetkom nekoliko onih koje su izgrađene u dvadesetprvom veku.

Ivični objekti blokova su u dobrom stanju, na fasadama nema skoro nikakvih oštećenja i generalno su dobro održavane. Osim krečenja i uklanjanja prljavštine od aerozagađenja veći poduhvati u vidu rekonstrukcije nisu potrebni.

Pešački pristup unutrašnjosti oba bloka moguć je samo iz Krunske ulice. Ovi prostori su prilično zanemareni i prepušteni volji pojedinaca koji su njihove delove zauzeli. Celom svojom površinom su asfaltirani i delom se koriste kao parking prostor. Izgrađeno je nekoliko prizemnih objekata koji imaju različite funkcije, od ekonomskih i objekata za stanovanje do komercijalnih delatnosti, koji su lošeg boniteta. Nema nikakvih sadržaja koji bi služili svim stanovnicima blokova, niti oplemenili ovako gusto izgrađen prostor. Osim malog broja stabala koji pružaju određeno zasenčenje primetno je odsustvo bilo kakve druge vrste vegetacije.

U okviru bloka A nalaze se dve manje uređene pejzažne celine, jedna u ulici Alekse Nenadovića, a druga u Krunskoj, kod pešačkog ulaza u unutarblokovski prostor. Drvoredi se pružaju duž Njegoševe i ulice Prote Mateje. U unutrašnjosti oba bloka nalazi se po nekoliko stabala drveća.

\subsection{Novoprojektovano pejzažno uređenje}

Odabrani blokovi za rekonstrukciju predstavljaju tipičan primer strukture blokovske gradnje na Vračaru, pa i u čitavom centru grada. Spadaju u zatvoren tip bloka.
Svi prizemni objekti lošeg boniteta iz unutarblokovskih prostora će biti uklonjeni. U bloku A takvih objekata ima tri, a u bloku B četiri. Stabla koja su zdrava i po poziciji se uklapaju u novo pejzažno rešenje će biti zadržana, dok će ostala biti posečena ili premeštena na drugu lokaciju.

Pešačke staze će povezati ulaze u dvorišta sa čitavim njihovim prostorom. Omogućiće kontinuirano kretanje korisnika i pristup svim sadržajima koje novoprojektovano rešenje nudi. Popločanje je od behaton ploča (na pesku, sa ispunom semena trave i humusa), zatim od PVC rastera i trave, koje pružaju neograničene mogućnosti spajanja ne/porozne i prirodne podloge. Pored pravilnog odabira debljine ploče, neophodna je i dobra priprema podloge koja će nositi kompletno opterećenje. U slučaju pešačkih staza i drugih površina, koje ne trpe velika opterećenja, tamponirani sloj je tanji.

Dvorišni mobilijar je od drveta i prati čitav koncept projekta. Savremeniji jednostavan dizajn i prirodne boje i materijali se uklapaju u celokupan prostor ne skrećući pažnju sa zelenila, istovremeno se uklapajući u prirodni ambijent. Klupe su raspoređene duž pešačkih staza i u većem broju su skoncentrisane kraj dečijih igrališta. Osim jednorednih klupa postavljene su i grupe elemenata od po dve klupe sa stolom između njih. Pružaju prostor za okupljanje većeg broja korisnika, igranje društvenih igara ili malih porodičnih izleta.

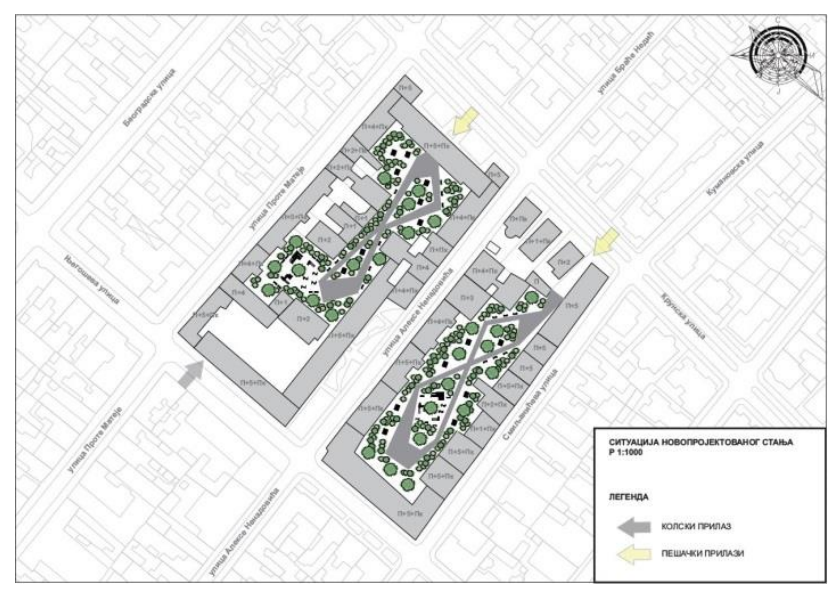

Slika 3. Situacija - predlog rešenja

Po jedno dečije igralište je smešteno u svakom bloku. Sadrže peljalice, klackalice i ljuljaške kako bi najmlađim korisnicima dvorišnog prostora obezbedili raznovrsne načine igre. Elementi igrališta su većinom izgrađeni od drveta jer ono kao prirodan materijal povezuje decu sa prirodom, estetski se uklapa u čitav koncept prostora i može se koristiti nesmetano tokom cele godine, jer se leti ne pregreva a zimi nije previše hladno. Moderni elementi predstavljaju čitave sisteme kula, tobogana, penjalica $\mathrm{i}$ mostova koji su međusobno povezani i pospešuju dečiju kreativnost, radoznalost $\mathrm{i}$ podstiču ih da provode vreme na otvorenom.

Kao podloga za dečija igrališta, korišćen je PVC raster element u kombinaciji sa travom, kao i tartan podloga. Ovakav način oblaganja podloge predstavlja betonsku rešetku koja je dizajnirana tako da se u njenim otvorima postavlja zemlja (ili neki drugi propusni materijal) u koju se sadi trava. Na taj način se delimično zastiru travom određene površine i rešava se propuštanje atmosferskih 
voda. Formiraju dobar prelaz između popločanih površina i trave, otporne su na klizanje i pružaju mogućnost brze i lake demontaže i rekonstrukcije nakon eventualnih intervencija na podzemnim instalacijama.

Duž pojedinih fasadnih zidova u unutrašnjosti oba bloka su instalirane vertikalne konstrukcije za indirektne zelene fasade. Pored toga što će pomagati stabilnosi puzavica zaštitiće i fasadu od oštećenja koje bi im same biljke mogle naneti. Takvi modularni rešetkasti sistemi mogu povećati otpornost biljaka na atmosferske uticaje i nude lako odvajanje od fasade u slučaju sanacije. Biće zasađene zimzelene puzavice (bršljan) koje će tokom cele godine oplemenjivati prostor u ulepšavati zidove.

Pored visokih stabala drveća, predviđena je visoka i niska žbunasta vegetacija. $\mathrm{Na}$ taj način biće postignuto diferenciranje prostora različite namene i promena dinamike u pejzažu. Zelene fasade neće u potpunosti biti zaklonjene od sunca, a vizure sa terasa okolnih objekata će biti bolje.

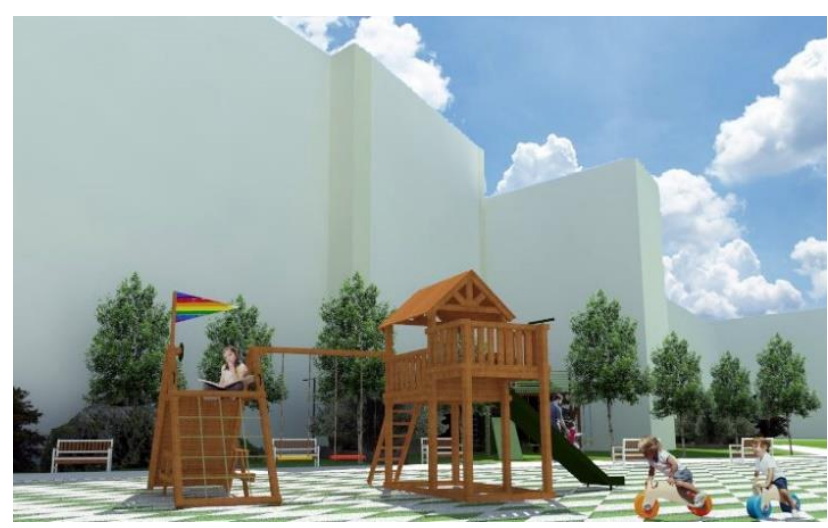

Slika 4. Trodimenzionalni prikaz novoprojektovanog prostora

\section{ZAKLJUČAK}

Sadašnje stanje unutarblokovskih prostora u Beogradu je rezultat decenijske nebrige i zanemarivanja ovih arhitektonskih celina. Nedostatak potrebnih mesta za parkiranje i samovolja pojedinaca od njih su napravili zapuštene prostore pune nelegalne gradnje, trošnih objekata i vozila. Malobrojne i po površini male travnate površine se ne održavaju i na kraju budu asfaltirane. Stanovništvo blokovskih celina nema izgrađen odnos prema tom prostoru jer ga ne smatra svojim.

U razvijenim zemljama se značaj pejzažno uređenih gradskih prostora prepoznaje. Analize uticaja nekontrolisane urbanizacije uvek se završavaju zaključkom da najviše trpe životna sredina i gradsko zelenilo. Pejzažnim uređenjem prostora između zgrada postiže se unapređenje kvaliteta životne sredine i umanjuju se razni negativni efekti urbanizacije, poput efekta toplotnog ostrva i zagađenja vazduha.
Uređenje unutarblokovskih prostora koje je obrađeno u ovom radu može predstavljati deo sistema mreže zelenila. Takav način rekonstrukcije centralnih jezgara mogao bi dovesti do velikog broja tačkastih zelenih prostora širom gradova. Bez velikih ulaganja i korišćenjem već izgrađenih struktura značajno se može uticati na poboljšanje ekološke slike i doprineti vizuelnom karakteru gradova.

\section{LITERATURA}

[1] V. Đokić i Z. Lazović, Uticaj klimatskih promena na planiranje i projektovanje, Univerzitet u Beogradu, Arhitektonski fakultet, 2011.

[2] B. Maksimović, Urbanizam, Beograd, Građevinska knjiga, 1957.

[3] V. Macura i J. Cvejić, Predlog mreže zelenila kao sredstva unapređenja životne sredine i slike grada na teritoriji opštine Vračar, Univerzitet u Beogradu, Šumarski fakultet, 1991.

[4] Lj. Vukajlov, Uvod u urbanizam, Univerzitet u Novom Sadu, Fakultet tehničkih nauka, 2015.

[5] Plan generalne regulacije građevinskog područja sedišta jedinice lokalne samouprave - grad Beograd (celine I-XIX) (,Službeni list grada Beograda“, br. 20/16, 97/16, 69/17, 97/17 i 9/20)

[6] Detaljni urbanistički plan rekonstrukcije četiri bloka na teritoriji opštine vračar između ulica: Alekse Nenadovića, Proleterskih brigada, Koče Kapetana i Njegoševe u Beogradu (,Službeni list grada Beograda", br. 5/88)

\section{Kratka biografija:}

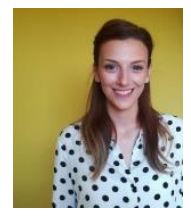

Višnja Damnjanović rođena je u Beogradu 1989. godine. Završila je Petu beogradsku gimnaziju i osnovne studije na fakultetu Union - Nikola Tesla. Master studije završava 2020. godine na Departmanu za arhitekturu i urbanizam, smer Arhitektonsko i urbanističko projektovanje.

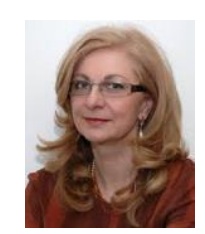

Mirjana Sekulić rođena 1955. godine u Zemunu. Doktorsku disertaciju pod nazivom „Razvoj i transformacije krovnog vrta od nastanka do savremenih tendencija" odbarnila je 2013. godine. Oblast interesovanja je pejzažna arhitektura. Vanredni je profesor na Departmanu za arhitekturu i urbanizam FTN u Novom Sadu. 